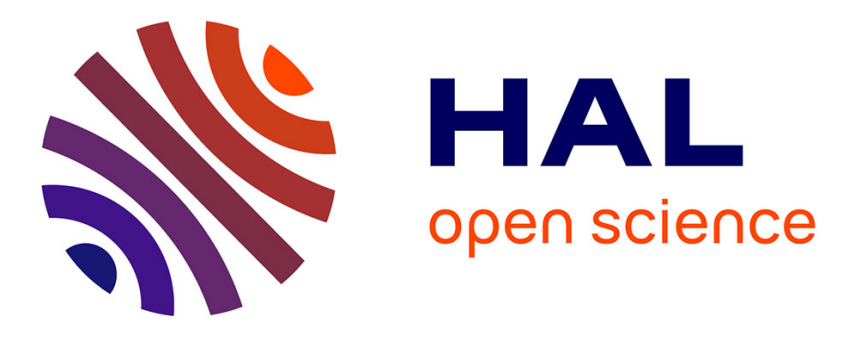

\title{
Influence of key parameters on the response of a resistive soot sensor
}

Didier Grondin, Alexandre Westermann, Philippe Breuil, Jean-Paul Viricelle, Philippe Vernoux

\section{- To cite this version:}

Didier Grondin, Alexandre Westermann, Philippe Breuil, Jean-Paul Viricelle, Philippe Vernoux. Influence of key parameters on the response of a resistive soot sensor . Sensors and Actuators B: Chemical, 2016, 236, pp.1036-1043. 10.1016/j.snb.2016.05.049 . hal-01316634

\section{HAL Id: hal-01316634 \\ https://hal.science/hal-01316634}

Submitted on 30 May 2016

HAL is a multi-disciplinary open access archive for the deposit and dissemination of scientific research documents, whether they are published or not. The documents may come from teaching and research institutions in France or abroad, or from public or private research centers.
L'archive ouverte pluridisciplinaire HAL, est destinée au dépôt et à la diffusion de documents scientifiques de niveau recherche, publiés ou non, émanant des établissements d'enseignement et de recherche français ou étrangers, des laboratoires publics ou privés. 


\title{
Influence of key parameters on the response of a resistive soot sensor
}

\author{
Didier. GRONDIN ${ }^{* \& *}$, Alexandre. WESTERMANN ${ }^{* *}$, P. BREUIL ${ }^{*}$, J.P. VIRICELLE* \& P. VERNOUX** \\ ${ }^{*}$ Ecole Nationale Supérieure des Mines, SPIN-EMSE, CNRS:UMR5307, LGF, 42023 Saint-Etienne, \\ France
}

Fax+33477499694 - email: viricelle@emse.fr

**Université de Lyon, Institut de Recherches sur la Catalyse et l'Environnement de Lyon, UMR 5256, CNRS, Université Claude Bernard Lyon 1, 2 avenue A. Einstein, 69626 Villeurbanne, France

Sensors and Actuators B: Chemical, Elsevier, DOI: 10.1016/j.snb.2016.05.049

\begin{abstract}
This paper is a comprehensive study dealing with the parameters that influence the response of a resistive soot sensor which was developed for Diesel Particulate Filter (DPF) failure detection in a past project. From the conductance measurement between two Pt electrodes, and a regeneration strategy, this kind of sensor can provide the weight concentration of particulate matter (PM). In this study, we have characterized and determined the key parameters such as the PM distribution size and the polarization voltage between the electrodes that could influence the sensor response. First results show that the sensor response strongly depends on the polarization voltage applied between the two electrodes.
\end{abstract}

Keys-words: Soot sensor; Resistive sensor, Particle Matter, On-Board diagnosis (OBD); Diesel particulate filter monitoring.

\section{Introduction}

Studies on vehicles exhausts have clearly demonstrated the negative effect of these emissions on the environment and the health [Barbusse and Plassat (2005)]. Emission legislations for Diesel engines become more and more stringent. The Particulate Matter (PM) emissions of automotive engines are now regulated in terms of mass and number. Since Euro 4 standards, Diesel light-duty vehicles have been equipped with Diesel particulate filters (DPF) to strongly reduce PM emissions. The PM accumulation into the inlet channels is determined by the pressure difference between the inlet and the outlet of the DPF. However, this system is not suitable to detect leaks and gives no information on the PM mass and number concentrations [Barbusse and Plassat (2005), Walker (2004)]. In order to meet the next European standards for PM emissions of Diesel light duty vehicles, an on-board diagnostic (OBD) sensor, able to detect DPF failures, is required. Therefore, the development of a cheap sensor effective for the measurement of both mass and particle number (PN) concentration is necessary. Resistive sensors are ones of the most promising solution for that purpose [Brunel et al. (2013), Grob et al. (2012), Hagen et al. (2010)]. They are typically composed of an alumina substrate, where the sensing face consists of two interdigitated platinum electrodes [ Brunel et al. (2013), Hagen et al. (2010), Husted et al. (2012), Ochs et al. (2010)]. The sensor response is the conductance (or the resistance) between these two electrodes, measured as a function of the soot loading. The distance between these two electrodes may be around $10 \mu \mathrm{m}$ to $100 \mu \mathrm{m}$ [Noulette and Duault (2014)]. During soot loading, an initial threshold time is required to observe a significant increase in the conductance because the PM collection does not yet form any electrical connections between the electrodes. The second phase corresponds to an increase of the conductance with time explained by soot bridges which are continuously formed between the electrodes [Brunel et al. (2013)]. When a polarization voltage is applied between the electrodes, the blind state (threshold time) is shorter because the production of dendrite-like paths is promoted [Brunel et al. (2013), Ochs et al. (2010)]. On the other side of the substrate, a platinum resistance is used to monitor and control the sensor temperature. Periodically, the soot accumulated on the sensing electrodes is removed during active regenerations by heating the sensor at around $600^{\circ} \mathrm{C}$. By performing several cycles of soot loading/regeneration, the sensor can give the PM mass concentration in pseudo real time with a response time of around 3 minutes [Brunel et al. (2013)]. 
Starting from past results on a resistive soot sensor development in the frame of "Ciclamen 2" French National project [Brunel et al. (2013)], the objective of the present study is to determine the impact of the PM size and concentration on the sensor response. Model soot particles issued form a gas burner have been produced with various characteristics in terms of size distributions, PN and mass concentrations. For each kind of model soot, the response of the sensor has been monitored versus time as a function of the polarization voltage between the two Pt electrodes. Although model soot may have slightly different physico-chemical properties than those of real diesel one, their size distribution, mass and number concentrations are realistic for the application. Moreover, the interest of model soot is obviously to have more reproducible conditions than with working with a real engines.

\section{Materials and methods}

\section{Soot sensor}

The sensor was developed in a previous work ("Ciclamen 2" national project) in collaboration with Electricfil Automotive car supplier Company. The sensor is made of an alumina substrate $\left(5^{\star} 0.5 \mathrm{~mm}^{2}\right)$. A platinum heater is deposited on opposite side to the sensing element which consists in interdigitated platinum electrodes deposited by screen-printing and laser engraving technics (Figure 1a-b) [Brunel et al. (2013), Noulette and Duault (2014)]. Using this latter method, the space between the two Pt electrodes is around $20 \mu \mathrm{m}$ as shown by SEM image in Figure 1c. which also reveals. An Insulating layer (blue color in Figure 1b) as deposited on the sensing side to define the collecting area of the soot particles as well as on the whole heater side to protect it against short circuits that could provoked by the soot.

a)

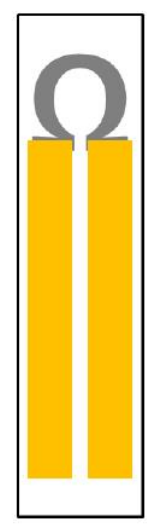

b)
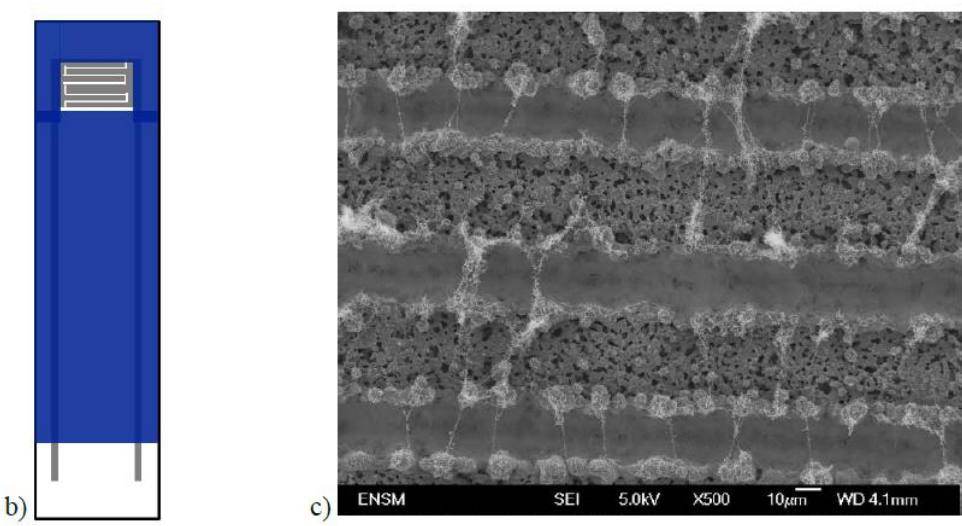

Figure 1. Schematic of the soot resistive sensor a) heater side, b) sensing side and c) SEM image of electrode area showing soot bridge.

The response of the sensor is defined as the conductance (or resistance) which is measured between the two platinum electrodes as a function of time, under controlled temperature and PM flow. Indeed, a stream of soot particles creates bridges between the two Pt electrodes (Figure 1c), by increasing the conductance. A polarization voltage is applied between the electrodes with a keithley 6430 Sub-Femtoamp Remote Sourcemeter which records the sensor conductance with time. The apparatus is monitored with a specific LabVIEW software. 


\section{Soot generation}

The soot generation was performed on a synthetic gas bench described elsewhere [LopezGonzalez et al. (2015)] and shown schematically in Figure 2.

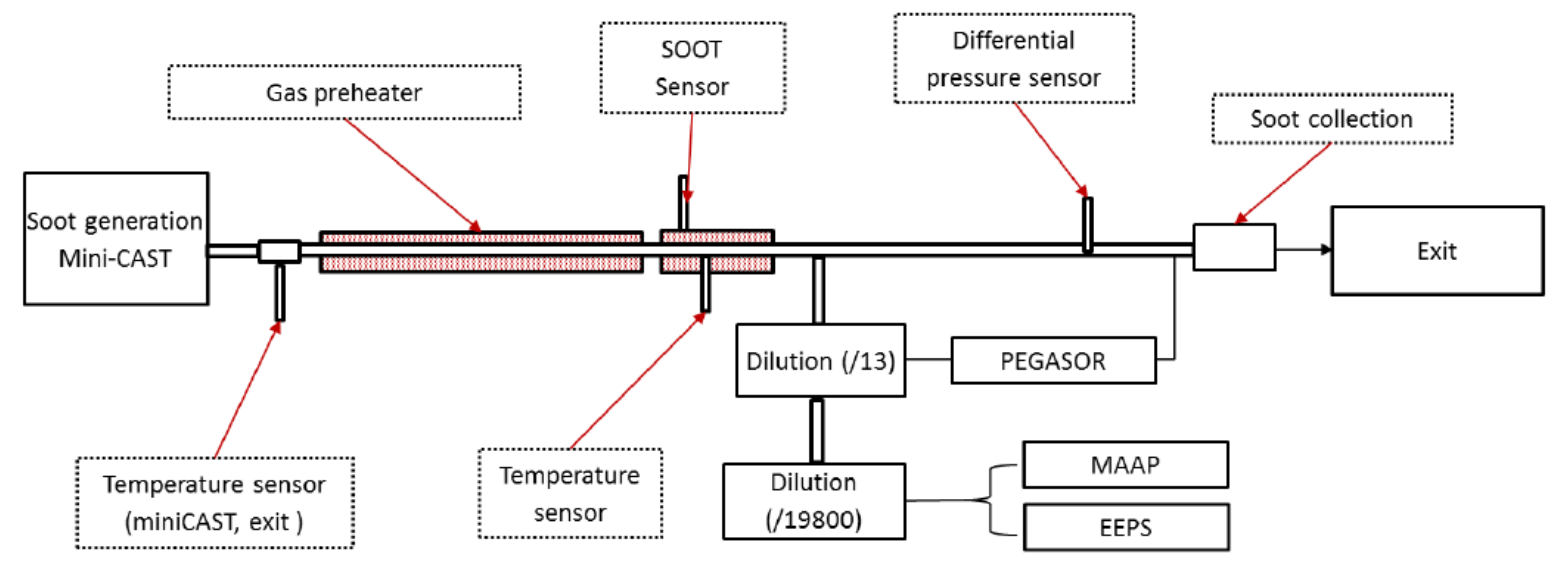

Figure 2. Schematic diagram of the synthetic test bench.

The bench is divided in 4 parts, the soot particles generator, a tubular oven to pre-heat the PM stream, the sensor and PM analytical tools.

Soot particles were produced with a mini Combustion Aerosol Standard burner (miniCAST 4202, Jing Ltd. Switzerland). Soot particles are formed within a co-flow diffusion flame due to the hydrocarbon pyrolysis (propane was used as a fuel) which takes place as a consequence of the heat provided by the oxidation at the flame front. The produced flame is quenched by a stream of nitrogen that enables at the same time the pyrolysis of the fuel, and the escape without being oxidized of the generated particles. The fuel to air ratio can be customized in order to obtain a broad range of flame conditions and consequently different types of soot particles (PN and size distribution) [Moore et al. (2014)]. An air flow of $1200 \mathrm{NL} / \mathrm{h}$ was added to dilute the PM stream. Four different operating points (OP) of the CAST burner, corresponding to four propane/air ratios (Table 1) have been used to produce different sizes and concentrations of soot particles. For each of these operating points, soot particles have been collected for ex-situ analysis. The soot collection was performed by thermophoretic deposition on the internal surface of an aluminum perforated block ( 1 inch diameter) and located just before the outlet of the bench.

The PM stream was preheated in a tubular furnace (THERMCONCEPT). The temperature control was performed by a retrofitted closed loop control system which controls the gas temperature at the exit of the oven (so close to the sensor).

The sensor is placed downstream the oven, perpendicularly to the pipeline with the sensing side back on stream to avoid direct impacts of particles on the sensing surface which could lead to a noisy signal. A K-type thermocouple was placed near the sensor (1 cm after the sensor) to record the gas temperature $\left(180^{\circ} \mathrm{C}\right)$. In order to control and characterize the PM produced, several on-line analyzers were positioned after the sensor as detailed in paragraph 2.3).

The conductance measurements were performed at the steady state conditions after the stabilization of temperature at the output of the miniCAST (around 1 hour after the flame ignition). The regeneration of the sensors was performed at $650^{\circ} \mathrm{C}$ for $3 \mathrm{~min}$.

\section{On-line Soot analysis}

Three complementary analyzers were used to characterize soot particles (size distribution, mass and number concentrations) generated by the miniCAST burner in our experimental tests conditions,

The PN and the size distribution were measured by an engine exhaust particle sizer spectrometer (EEPS model 3090, TSI Inc.) which can quantify PM size from 22 to $560 \mathrm{~nm}$ with a sizing resolution of 16 channels per decade (i.e., total 32 channels). Measurements are performed at a frequency of 10 $\mathrm{Hz}$ allowing a real time analysis. Overview of the principle can be found in reference [Burtscher (2005)]. 
In addition, the black carbon concentration in the soot was measured with a Multi-angle Absorption Photometer (MAAP). This analysis is based on the light absorption of the black carbon that is collected on a fiber glass [Burtscher (2005)] Hence, MAAP analyzer does not give any information on the organic fraction. Although the specific extinction coefficient may slightly vary with the PM size [Fuller et al. (1999)], it was kept constant for the various OPs used in our study. Indeed, MAAP measurements applied to urban and background aerosol have shown a strong correlation between black carbon mass concentration and aerosol light adsorption despite a wide size distribution [Petzold and Schönlinner (2004)].

Three ejector diluters (2 Palas VKL 10, 1 Palas VKL 100) [Burtscher (2005)] have been connected in series to achieve soot concentrations levels below the upper measurement ranges of the EEPS and the MAAP. The overall dilution ratio was 19800 .

Finally, a PEGASOR particle sensor analyzer (PPS) was placed after the first diluter system (VKL 10 diluter, dilution ratio 13) to online follow the soot mass concentration. This latter is measured from the leak current of charged particles [Ntziachristos et al. (2013)]. The trap was set at 400V as recommended by the constructer. PPS response is sensitive to soot composition and size, and should be calibrated for each OP to perform an accurate quantitative analysis. However, in the present study, PPS analyzer was mainly used to check the reproducibility between various tests at a given OP, and the stability of soot generation over time.

\section{Characterizations of collected soot.}

The structure and size of the collected soot at each mini-CAST operation conditions have been observed with a Transmission Electronic Microscope (TEM, JOEL 2010 LaB6). The acceleration voltage applied was $200 \mathrm{kV}$ and the resolution point was $0.19 \mathrm{~nm}$. The samples were previously dispersed in ethanol using an ultrasonic bath and deposited on a measurement grid.

Temperature programmed oxidation (TPO) measurements have been performed to evaluate the reactivity of the different soot. The collected soot was mixed with an inactive SiC powder (weight ratio soot $/ \mathrm{SiC}=1 / 5)$ for 5 minutes with a ball-grinder. TPO were also conducted using Printex $\mathrm{U}$, a commercial black carbon powder, for comparison. The soot weight varies in the range $2-5 \mathrm{mg}$ (Table 2). The samples were then introduced in a tubular furnace. The reaction temperature was measured with a K-type thermocouple located close to the sample. The temperature was increased at the rate of $10^{\circ} \mathrm{C} / \mathrm{min}$ up to $750^{\circ} \mathrm{C}$. The composition of the gas mixture was $5 \%$ of oxygen (Linde Gas, $99.995 \%$ purity) in helium. The flow rate was kept constant at $6 \mathrm{~L} / \mathrm{h}$. Gas emissions were recorded during the heating ramp. $\mathrm{CO}$ and $\mathrm{CO}_{2}$ production were monitored using an infrared analyzer (EMERSON NGA 2000) while $\mathrm{O}_{2}$ concentrations were measured by gas chromatography using a micro-chromatograph (SRA 3000). Soot conversion (\%) was calculated as the ratio of cumulative $\left(\mathrm{CO}+\mathrm{CO}_{2}\right)$ quantity at the considered temperature, to the total $\left(\mathrm{CO}+\mathrm{CO}_{2}\right)$ quantity at the end of TPO experiment where we assume that soot is totally converted. In addition, a mass spectrometer (Pfeiffer vacuum PrismaPlus QME220) was used to obtain complementary qualitative information on the soot chemical composition.

Raman spectra of the collected soots were recorded with a LabRam HR Raman spectrometer (Horiba-Jobin Yvon) equipped with BXFM confocal microscope, interference and Notch filters and CCD detector. The exciting line at $514.5 \mathrm{~nm}$ of a $2018 \mathrm{RM} \mathrm{Ar}^{+}$laser (Spectra Physics) was focused using a $\times 50$ long working distance objective. The influence of the laser power was investigated from 10 to $1000 \mu \mathrm{W}$ (not discussed in this study) and $\mathrm{P}=100 \mu \mathrm{W}$ was chosen as the working power. Indeed, the focusing of a laser on materials can locally heat depending on its power and lead to structural and chemical evolutions. Spectra collected with gratings of 300 grooves. $\mathrm{mm}^{-1}$ were accurate within $4 \mathrm{~cm}^{-1}$ (with a laser spot diameter of $1 \mu \mathrm{m}$ ). The instrument was calibrated against the Stokes Raman signal of pure Si at $521 \mathrm{~cm}^{-1}$ using a silicon wafer ((111) crystal plane surface). All recorded data were treated using the Labspec software (Horiba-Jobin Yvon). Spectra were fitted after the multipoint baseline correction by combination of five Lorentzian-shaped G, D1, D2, D3 and D4 bands at about 1580, 1350, 1620, 1500 and $1200 \mathrm{~cm}^{-1}$ [Sadezky et al. (2005), Ivleva et al. (2007)]. 
The apparent electrical conductivity of soot was estimated at room temperature in air by using a specific cell developed to fit with the low soot quantity that can be collected during the test. The cell consists in a Teflon block with an internal diameter of $1.5 \mathrm{~mm}$ with a brass piston at the top and a brass plate at the bottom, connected to a resistor meter. However, conductivity values were found to be strongly dependent on the soot packed-bed arrangement in the cell. Only range of order could be determined, leading to around $50 \mathrm{~S} . \mathrm{m}^{-1}$ for OP1 and to nearly $0.3 \mathrm{~S} . \mathrm{m}^{-1}$ for OP5 at $20^{\circ} \mathrm{C}$. It must be taken into account that these values do not represent the intrinsic soot conductivity but an overall conductivity including carbon and organic fractions. In addition, the conductance measured on sensors may strongly depend on the structure of soot bridges between electrodes.

\section{Results and discussion}

\section{On-line PM characterizations.}

The soot produced by the CAST burner depends on the richness of the propane/air mixture (Table 1). Size distributions measured by the EEPS analyzer are shown in Figure 3.

Table 1. Soot characteristics produced by the soot generator (MiniCAST) depending on the operating point (OP).

\begin{tabular}{ccccc}
\hline $\begin{array}{c}\text { Operating } \\
\text { Point }\end{array}$ & $\begin{array}{c}\text { Richness of } \\
\text { propane/air } \\
\text { mixture }\end{array}$ & $\begin{array}{c}\text { PN } \\
\text { (EEPS) } \\
\text { particles/cm }\end{array}$ & $\begin{array}{c}\text { Mass } \\
\text { concentration } \\
\text { (PEGASOR) } \\
{\mathrm{mg} / \mathrm{m}^{3}}^{3}\end{array}$ & $\begin{array}{c}\text { Carbon } \\
\text { black } \\
\text { (MAAP) } \\
\mathrm{mg} / \mathrm{m}^{3}\end{array}$ \\
\hline OP1 & 0.97 & $1.7 \mathrm{E}+8$ & 94 & 143 \\
OP1B & 0.97 & $1.2 \mathrm{E}+8$ & 61 & 81 \\
OP4 & 1.00 & $2.5 \mathrm{E}+8$ & 91 & 70 \\
OP5 & 1.02 & $2.1 \mathrm{E}+8$ & 55 & 22 \\
\hline
\end{tabular}

Four operating Points (OP) of the burner have been defined to produce various PM sizes and concentrations. Two OPs (OP1 and OP1B) correspond to the same richness but with lower propane and air flows for OP1B (Table 1). The two instruments, PEGASOR and MAAP, give quite different values of mass concentrations. According to the photometer, the PM mass concentration strongly decreases with richness in the flame from OP1 to OP5 (Table 1). These measurements are based on the light absorption of black carbon. Therefore, one can assume that this apparatus is more sensitive to large soot particles, mainly composed of a carbon core. This is in good agreement with the drop of $\mathrm{PN}$ above $100 \mathrm{~nm}$ when the richness in the flame increases (Figure 3).

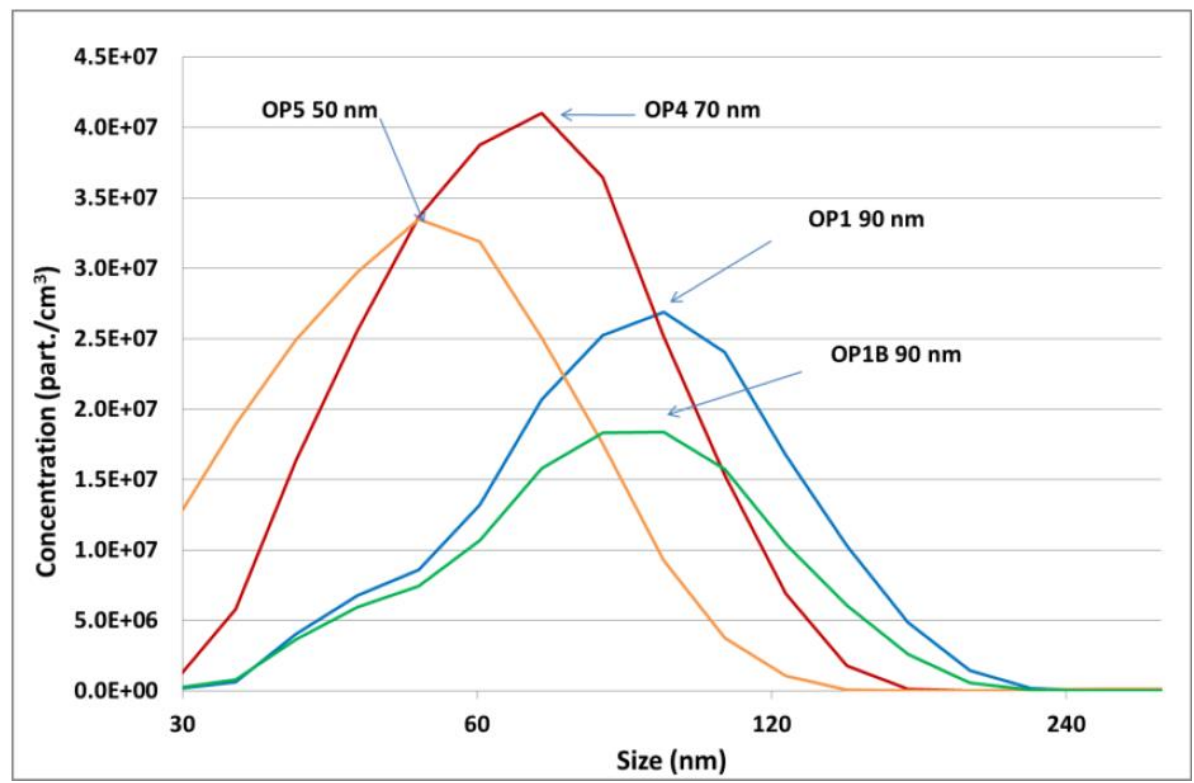

Figure 3. Size distribution of the different OPs (EEPS measurement). Concentrations correspond to values before dilution (dilution factor $=19800$ ). 
On the other hand, the PEGASOR analyzer is measuring a leak current extracted from the PM electrical charge. This latter parameter most probably varies with the CAST OP, i.e. the chemical nature of the soot, leading the comparison between the different OPs quite speculative. For OP1 and OP1B, two similar tunings, the responses of the PEGASOR show similar trends than those of the photometer but for OP4 and OP5, results are quite different. Therefore, we have considered that the PM mass concentration estimated by the MAAP is more suitable to compare the different OPs.

When the propane/air ratio in the flame increases, the PM mass concentration decreases while the size distribution is shifted to lower values (Figure 3 and Table 1). For instance, the PM diameter at the maximum of the Gaussian distribution is around $90 \mathrm{~nm}$ for OP1 and OP1B, $70 \mathrm{~nm}$ for OP4 and $50 \mathrm{~nm}$ for OP5. As expected, OP1 and OP1B lead to a similar size distribution (Figure 3), but with a lower mass and PN concentration for OP1B. The ratio of the propane flows between OP1 and OP1B was approximately 1.2. This value is fairly similar to the mass concentration ratios between OP1 and OP1B measured by the different instruments: 1.4 (EEPS), 1.5 (PEGASOR) and 1.8 (MAAP). Regarding the overall PN, concentrations are fairly similar at around $210^{8}$ part $/ \mathrm{cm}^{3}$ for OP1, OP4 and OP5 (Table 1). For OP1B, the lower flow of propane explains the smaller PN around $10^{8}$ part $/ \mathrm{cm}^{3}$.

\section{Temperature Programmed Oxidation of collected soot}

The reactivity of the soot was evaluated from Temperature Programmed Oxidation (TPO) experiments (Figure 4).

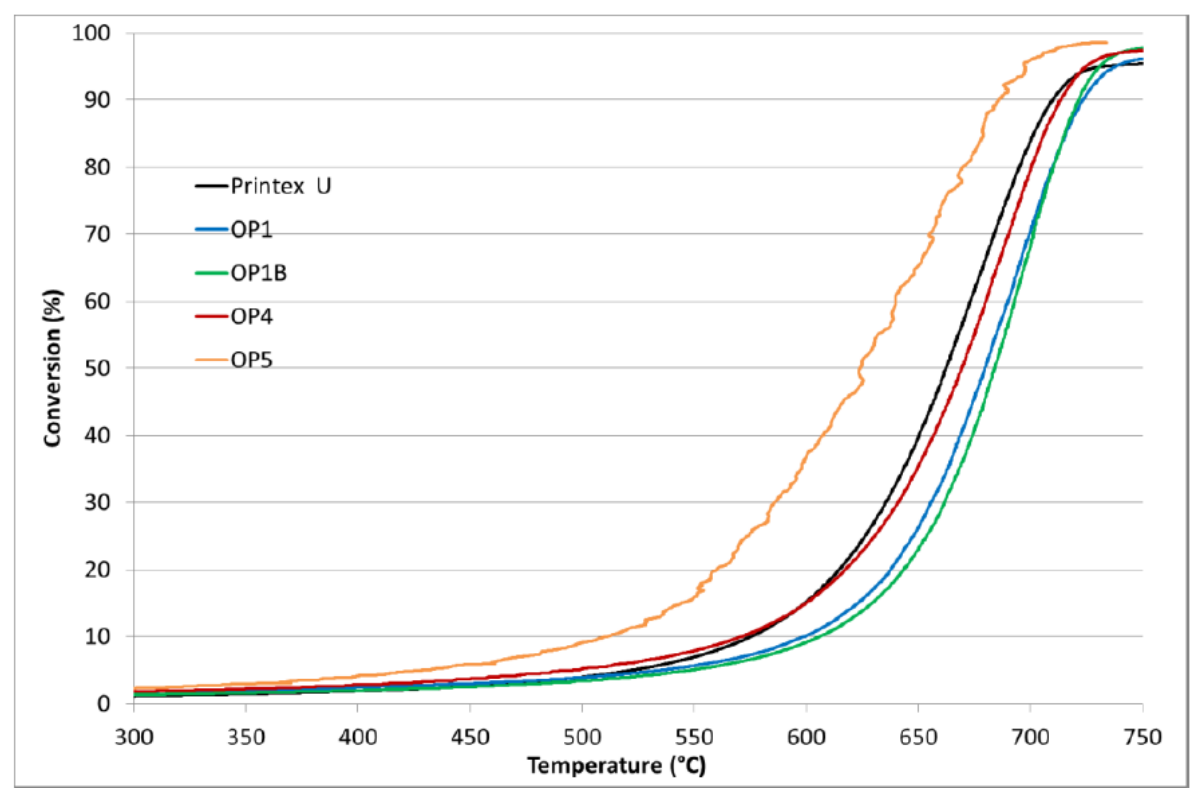

Figure 4. Soot conversion as a function of temperature for the different CAST soot measured from TPO experiments.

The soot oxidation beginning was fixed when the derivative of the conversion curve was higher than an arbitrary value $(0.03)$. The soot oxidation starts at $326^{\circ} \mathrm{C}$ for $\mathrm{OP} 5,493^{\circ} \mathrm{C}$ for Printex $\mathrm{U}, 496^{\circ} \mathrm{C}$ for OP $4,525^{\circ} \mathrm{C}$ forOP 1 and $529^{\circ} \mathrm{C}$ for OP1B (Table 2 and Figure 4).

Table 2. TPO results summary for the different OPs $\left(T_{\text {oxidation }}\right.$ is the observed starting oxidation temperature; $T_{10}$ is the temperature corresponding to $10 \%$ conversion of the soot).

\begin{tabular}{cccc}
\hline $\begin{array}{c}\text { Operating } \\
\text { Point }\end{array}$ & $\begin{array}{c}\text { Soot mass } \\
\mathrm{mg}\end{array}$ & $\begin{array}{c}\mathbf{T}_{\text {oxidation }} \\
{ }^{\circ} \mathrm{C}\end{array}$ & $\begin{array}{c}\mathbf{T}_{\mathbf{1 0}} \\
{ }^{\circ} \mathrm{C}\end{array}$ \\
\hline Printex U & 5.3 & 493 & 575 \\
OP1 & 2.4 & 525 & 599 \\
OP1B & 3.1 & 529 & 606 \\
OP4 & 2.2 & 496 & 571 \\
OP5 & 3.5 & 326 & 510 \\
\hline
\end{tabular}


The parameters $T_{10}$ (Table 2), corresponding to the temperature at $10 \%$ conversion of soot, was used to compare the reactivity. Values of $\mathrm{T}_{10}$ (Table 2$)$ follow this rank: OP5 $\left(510^{\circ} \mathrm{C}\right)<\mathrm{OP} 4 \approx$ Printex $\mathrm{U}\left(570^{\circ} \mathrm{C}\right)<\mathrm{OP} 1 \approx \mathrm{OP} 1 \mathrm{~B}\left(600^{\circ} \mathrm{C}\right)$. This indicates that soot reactivity increases with the richness in the flame. This difference in reactivity may be due to different chemical compositions or surface specific areas or also soot structure organization, as observed by Grob et al (2012). However, one can note that TPO experiments confirm that OP1 and OP1B produce similar PM with the same reactivity. Three kinds of PM can be determined from TPO (Figure 4) and on-line characterizations (Table 1). OP5 produces more reactive particles containing a higher organic fraction compared to those generated by OP1 and OP1B. This was also supported by Temperature-Programmed Desorption (TPD) under vacuum of the different soot up to $850^{\circ} \mathrm{C}$ (not shown here). In particular, the monitoring of $\mathrm{m} / \mathrm{z} 15$ and 29 signals during a heating ramp $\left(20^{\circ} \mathrm{C} / \mathrm{min}\right)$ has confirmed the highest concentration of organic compounds on the OP5 soot. ., OP4 soot particles present intermediate properties whereas the desorption of organics from OP1 and OP1B only takes place from $750^{\circ} \mathrm{C}$ and is rather limited. Such classification is also in agreement with MAAP measurements (Table 1) which point out that the black carbon content decreases from OP1 to OP5. It appears also coherent with apparent soot electrical conductivity measurements (section 2.4) as lower black carbon fraction leads to lower conductivity.

\section{TEM observations}

The PM structure and size have been observed by TEM. The results presented in Figure 5 show that the produced PM have the same structure as emitted by a Diesel engine [Liati et al. (2013)]. The soot is composed of primary spherical particle agglomerated in a bigger particle with a fractal shape (Figure $5 \mathrm{a}, \mathrm{b}, \mathrm{c}$ ). The primary particles have a similar size for each OPs, around $20 \mathrm{~nm}$ organized with a turbostratic arrangement of the graphene lamellae spaced of around $0.3 \mathrm{~nm}$ (Figure $5 \mathrm{~d}, \mathrm{e}, \mathrm{f}$ ). No significant difference was found between each OPs.

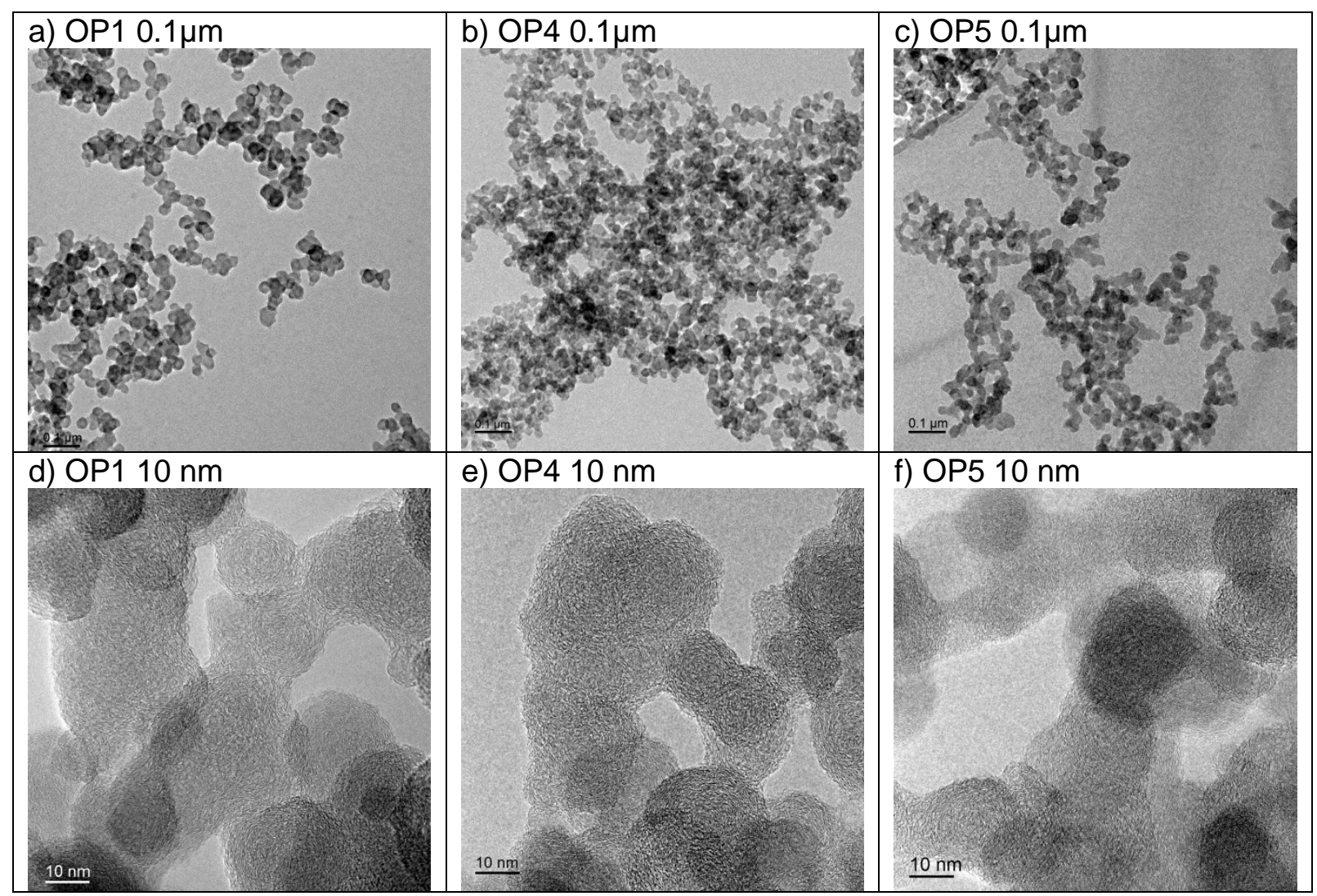

Figure 5. TEM observations for OP1 (a, d), OP4 (b, e), and OP5 (c, f) at $0.1 \mu \mathrm{m} \mathrm{(a-c)} \mathrm{and}$ $10 \mathrm{~nm}(\mathrm{~d}-\mathrm{f})$ scale. 


\section{Raman spectroscopy characterizations}

Figure 6 shows characteristic visible Raman spectra of the collected PM with no correction of the baseline.

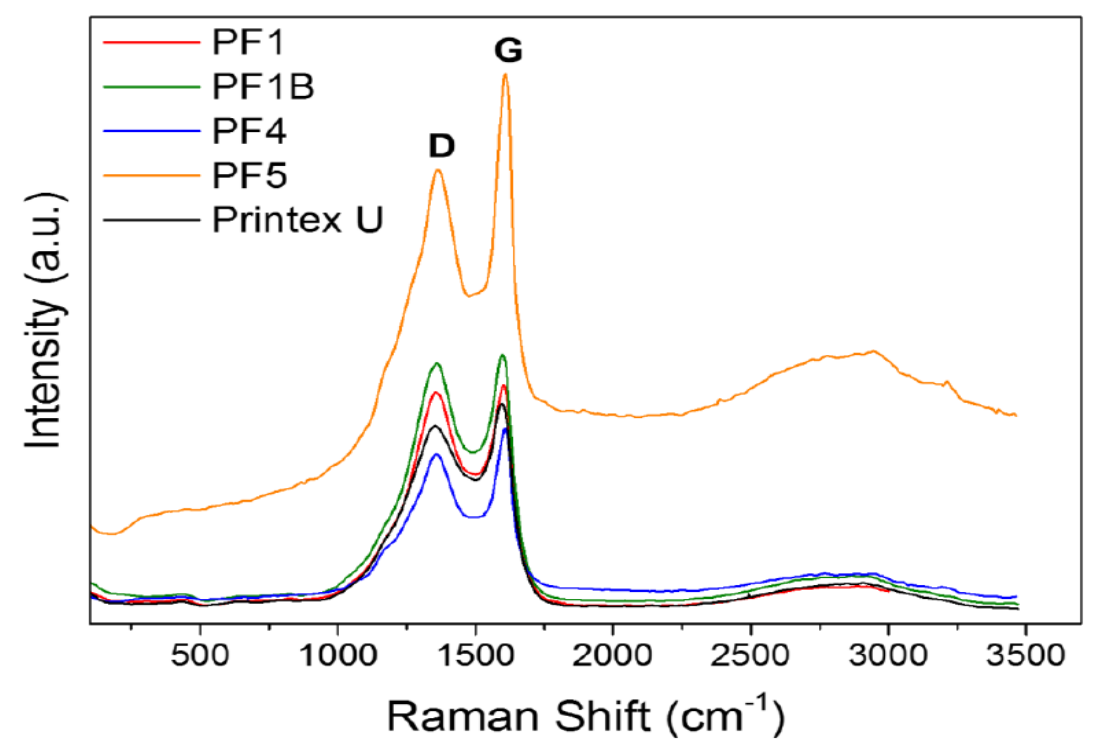

Figure 6. Characteristic Raman spectra of the collected soot using an exciting line at $\mathbf{5 1 4 . 5} \mathbf{~ n m}$.

We have observed quite different backgrounds due to fluorescence between OP5 soot spectra and those of the others PMs. This level of fluorescence is mainly due to presence of adsorbed organics on the surface [Uy et al. (2014)]. This indicates that OP5 PMs contain a much larger surface concentration of organic compounds. This confirms the result observed on OP5 soot with TPO experiments. The Raman spectra are all composed of two broad and overlapping bands centered at $1355-1360 \mathrm{~cm}^{-1}$ (with a shoulder at $1180 \mathrm{~cm}^{-1}$ ) and $1575-1595 \mathrm{~cm}^{-1}$ corresponding respectively, according to the literature, to the $D$ and $G$ of amorphous and graphitic carbon [Ivleva (2007)]. According to previous studies [Sadezki et al. (2005)], these broad bands can be fitted in multiple D bands, i.e. D1, D2, D3, D4 located at about $1350 \mathrm{~cm}^{-1}$ (D1), $1620 \mathrm{~cm}^{-1}$ (D2), $1500 \mathrm{~cm}^{-1}$ (D3), $1220 \mathrm{~cm}^{-1}$ (D4) as well as the $G$ band at $1580 \mathrm{~cm}^{-1}$. This latter corresponds to the ideal graphitic lattice $\left(E_{2 g^{-}}\right.$ symmetry) while the $D$ bands (or "Defect" bands) are associated with disordered graphitic lattice and amorphous carbon for D3. The lower the G/D intensity ratio, the more disordered (less graphitic) the material is. The $A_{D 1} / A_{G}$ band area ratios are commonly used to describe the structural order of soot. Values of this ratio are quite similar and comprised between 3.1 and 6.25 for OP5 and OP1B, respectively (Table 3).

Table 3. Main characteristics of the different soot Raman spectra.

\begin{tabular}{cccccccc}
\hline $\begin{array}{c}\text { Soot } \\
\text { type }\end{array}$ & \multicolumn{3}{c}{ Band position $\left(\mathbf{c m}^{-1}\right)$} & \multicolumn{3}{c}{ FWHM $\left(\mathbf{c m}^{-1}\right)$} & A 1 1 $^{-1} \mathbf{A}_{G}$ \\
\hline & D1 & D3 & G & D1 & D3 & G \\
\hline $\begin{array}{c}\text { Printex } \\
\text { U }\end{array}$ & 1357 & 1504 & 1581 & $213 \pm 13$ & $135 \pm 24$ & $69 \pm 11$ & $4.68 \pm 1.6$ \\
OP1 & 1357 & 1509 & 1579 & $194 \pm 6$ & $120 \pm 16$ & $70 \pm 12$ & $5.97 \pm 2.0$ \\
OP 1B & 1355 & 1511 & 1578 & $200 \pm 6$ & $119 \pm 17$ & $67 \pm 12$ & $6.25 \pm 2.0$ \\
OP 4 & 1358 & 1512 & 1589 & $170 \pm 4$ & $128 \pm 13$ & $64 \pm 6$ & $4.25 \pm 0.9$ \\
OP 5 & 1365 & 1530 & 1594 & $151 \pm 4$ & $239 \pm 11$ & $56 \pm 4$ & $3.10 \pm 0.5$ \\
\hline
\end{tabular}


For comparison, the $A_{D 1} / A_{G}$ ratio of the pure graphite is approximately 0.2 while that of a Diesel soot is around 4.2 [Sadezki et al. (2005)]. This underlines that PMs produced by the CAST burner have a similar carbon organization than that of real Diesel soot. The $A_{D 1} / A_{G}$ ratio seems to slightly decrease with the richness in the flame, suggesting that OP5 PMs are more graphitic than OP1 soot. If soot reactivity was only linked to graphitic state, this result would be in contradiction with TPO experiments (Figure 4).It means that the main difference is the organic fraction content, higher for OP5, in agreement with TPO results and the background of Raman spectra. The difference in the graphitic level is rather small as also observed by TEM.. In addition, the difficult deconvolution of the broad spectral range into multiple and strongly overlapping bands leads to inaccurate determination of the $A_{D 1} / A_{G}$ ratio (with a standard error up to $30 \%$ for OP1 and OP1B PMs). It was shown by Sadezki et al. (2005), that the full widths at half maximum (FWHM) of the different bands, and specifically that of D1, is more precise to estimate the degree of the structural order of PMs. The FWHM of the D1 peak was found to decrease with the graphitic organization. Table 3 shows that the D1 band FWHM is in the range $151-194 \mathrm{~cm}^{-1}$ while that of the graphite is approximately at $45 \mathrm{~cm}^{-1}$ and a Diesel soot at $174 \mathrm{~cm}^{-}$ 1 . These results confirm that the structural order of the CAST soot is similar to that of Diesel soot. Raman spectroscopy also clearly underlines that OP1 and OP1B soot present similar structural order.

\section{Soot sensor responses}

The variations of the sensor conductance with time during the soot loading for the different OPs upon different polarizations voltage are reported on Figure 7.
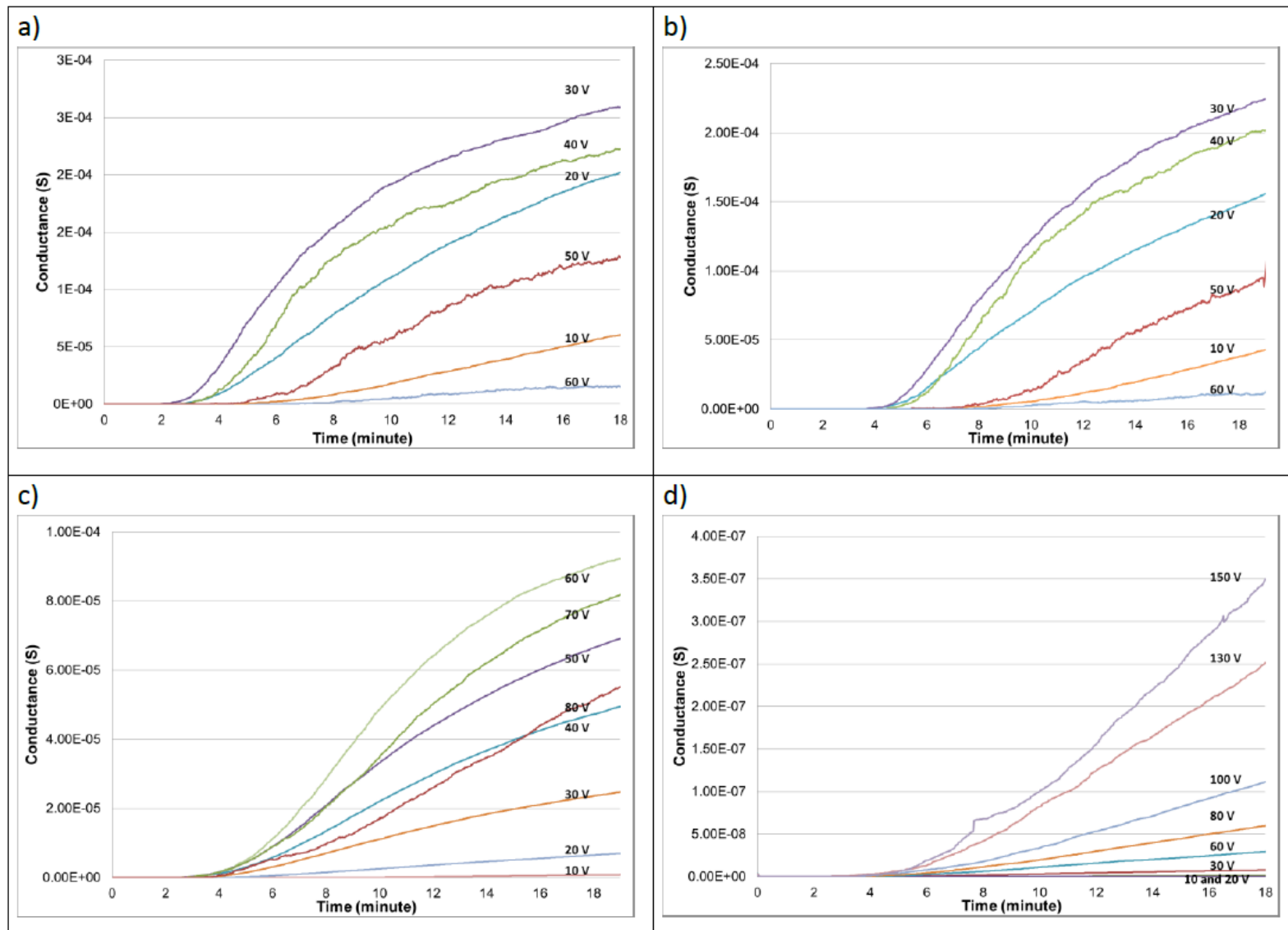

Figure 7. Variation of the conductance with time for different polarization voltages and miniCAST OPs: OP1 a) OP1B b) OP4 c) and OP5 d). 
These tests were carried out on the same sensor for each OP. The polarization voltage range was $10-60 \mathrm{~V}$ for OP1 and OP1B, $10-80 \mathrm{~V}$ for OP4 and up to $150 \mathrm{~V}$ for OP5. The conductance measurements were performed during several cycles (soot loading / regeneration) for a stable temperature at $180^{\circ} \mathrm{C}$ of the PM stream. The initial time on Figure 7 corresponds to the end of a regeneration phase, i.e. no PM collected on the sensing Pt electrodes. The conductance was measured for 18 minutes. The curves present a sigmoid profile. The first part of these curves corresponds to the formation of the first connections (percolation time), i.e. first bridges between the two Pt electrodes. Then, the second part corresponds to the continuous formation of soot bridges between the electrodes as shown in Figure 1. Once the inter-electrodes space becomes more or less saturated with soot bridges for longer exposure time (not shown in Figure 7), the conductance reaches more or less a plateau. Soot continues to deposit on the sensing element as a layer but the contribution to the global conductance becomes negligible as no additional conducting bridge is formed between electrodes. Moreover, this situation has no real interest regarding neither comprehension of size or number effect as the sensor is saturated, nor application as the sensor will have to be regenerated at quite lower accumulation time. The conductance increase rate, corresponding to the soot collection rate on sensing electrodes strongly depends on the polarization voltage (Figure 7). Except for OP5, there is an optimal voltage corresponding to the higher collection rate. This latter is $30 \mathrm{~V}$ for OP1 and OP1B, and $60 \mathrm{~V}$ for OP4. For OP5, despite the fact that the voltage applied reached $150 \mathrm{~V}$, no optimal voltage has been achieved (Figures 7 and 8).

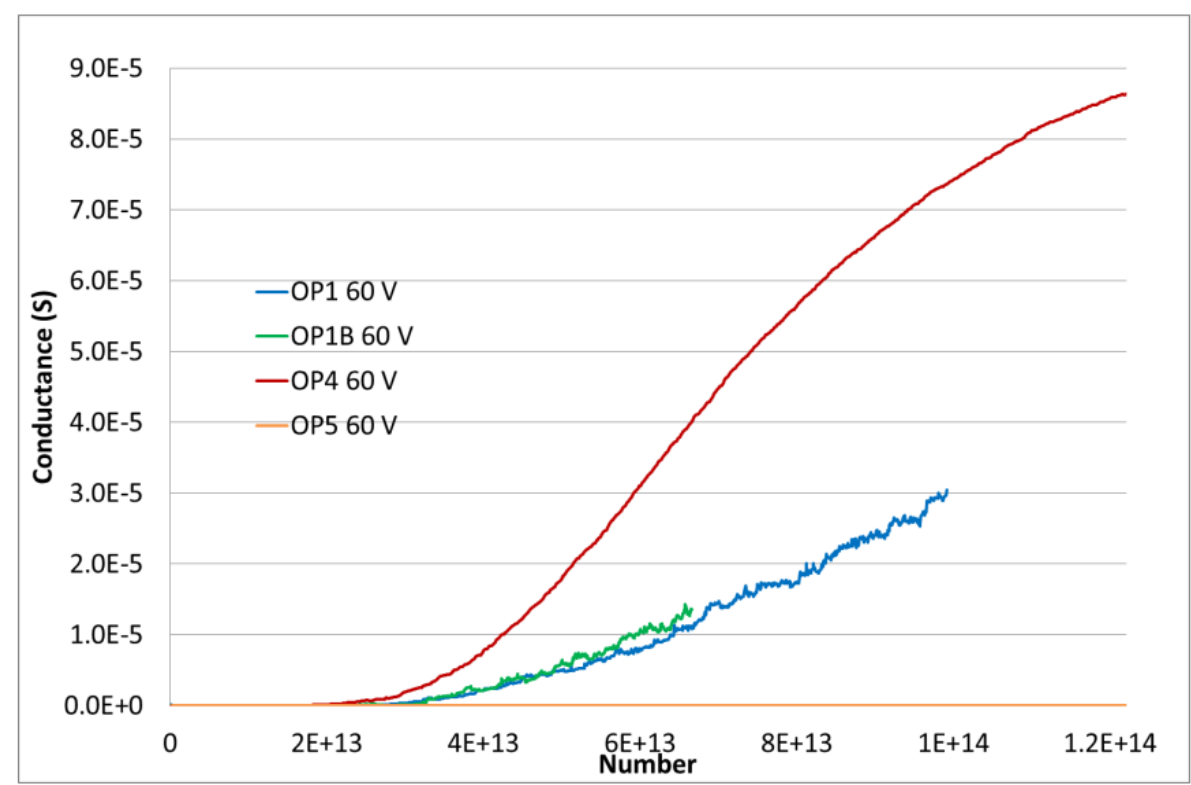

Figure 8. Variation of the conductance as a function of cumulative particle exposed number for $60 \mathrm{~V}$ polarization for each OP.

Upon optimal polarization, the sensor responses are different for each OPs. After $18 \mathrm{~min}$ on PM stream, the conductance values, for the optimum voltage, follow this rank: $300 \mu \mathrm{S}(\mathrm{OP} 1)>225 \mu \mathrm{S}$ (OP1B) >> $90 \mu \mathrm{S}$ (OP4) >> $0.4 \mu \mathrm{S}$ (OP5) (Figure 7). This is in good agreement with the mass concentration measured by the MAAP (table 1) which gives the same ordering. Therefore, the value of conductance measured at a given time after percolation step, under optimal polarization, is linked to the black carbon content into the soot.. This result is also coherent with both the apparent electrical conductivity measurement of OP5 soot which is two orders of magnitude lower than that of OP1 (section 2.4), as well as the TPO experiments which indicate that the reactivity increases (decreases) with the organic (black carbon) content. Figure 7 also allows to determine the percolation times as a function of the polarization voltage for each OP. They are in the range $1.8-3.9 \mathrm{~min}$ for OP1, $3-5 \mathrm{~min}$ for OP1B, $1.6-6.3 \mathrm{~min}$ for OP4 and $2.5-7 \mathrm{~min}$ for OP5. Percolation times are not so different and cannot be linked to the PM mass concentration. For instance, a 4 times smaller mass concentration does not significantly modify the percolation time recorded for OP5 compared to OP1B (Table 1). On the other hand, the twice PN of OP1 compared to OP1B leads to a shorter percolation time: $1.8 \mathrm{~min}$ instead of $3 \mathrm{~min}$. This indicates that the percolation time could be linked to the number of particles for similar size distribution. To check this hypothesis, conductance variations are represented as a function of the cumulative PM number calculated as the product of PN concentration measured by EEPS $\left(\right.$ particle $\left./ \mathrm{cm}^{3}\right)$ by the flow $\left(\mathrm{cm}^{3} / \mathrm{h}\right)$ and the time $(\mathrm{h})$. 
Figure 8 reports such curves for each OP at a fixed polarization voltage of $60 \mathrm{~V}$. It can be seen that sensor responses for OP1 and OP1B having the same size distribution (Figure 3) but different PN concentrations are similar. Hence, the correlation between percolation time and particle number seems to be valid for a given type of particles. Moreover, Figure 8 also reveals that OP1, OP4 and OP5 curves are different, highlighting that size distribution and electrical apparent conductivity are the key parameters.

In order to point out the optimal polarization voltage corresponding to each OP, Figure 9 presents the time to achieve a conductance value of $10^{-7} \mathrm{~S}$ versus the polarization voltage extracted from Figure 7 results. The optimum polarization voltages, corresponding to the minima of the invertedvulcano curves, seem to be inversely proportional to the PM size. The smallest the PM size, the highest the optimal polarization voltage is. Indeed, despite different PM mass concentrations, the optimal polarization voltage of the sensor exposed to a PM stream produced by OP1 and OP1B is similar.

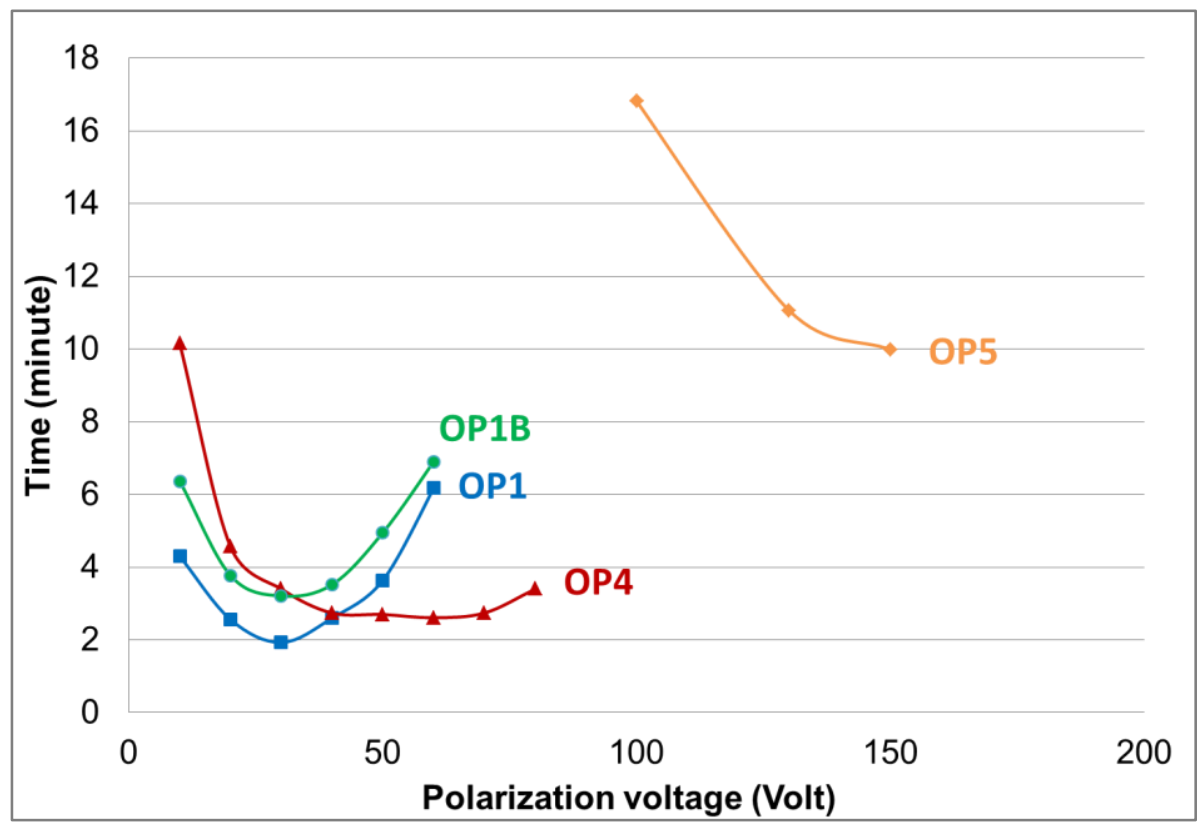

Figure 9. Loading time to reach 10-7 S versus the polarization voltage for the different OPs.

\section{Conclusion}

This study describes the impact of the PM size and concentration on the responses of a resistive sensor. Model soot particles have been produced with various characteristics in terms of size distributions, number and mass concentrations and collected onto two interdigitated Pt electrodes upon different polarization voltages. Analysis of the sensor responses curves, i.e. variation of the conductance with time, allowed to draw correlations between some characteristics like the percolation time, the optimal polarization voltage and the conductance value with the soot properties. This conductance value is clearly linked to the PM mass concentration and PM composition (organic fraction), while the percolation time seems to be more related with the PN concentration.

Finally, the optimal polarization voltage appears to be dependent on the PM size. These demonstrative results will be useful in the development of a soot sensor for PN measurement. In order to go further, a physical model based on soot collection between polarized electrodes is under development.

\section{Acknowledgments}

The authors wish to acknowledge "Arc Environnement" from Region Rhone-Alpes for the funding and EFI automotive car supplier for sensors manufacture. 


\section{References}

Barbusse S. \& Plassat G. (2005): Particules de combustion automobile et leurs dispositifs d'élimination (Les). ADEME report, $n^{\circ} 5728$, France, 128 p.

Brunel O., Duault F., Lavy J., Creff Y. \& Youssef B. (2013): Smart Soot Sensor for Particulate Filter OBD. SAE International Journal of Passenger Cars - Electronic and Electrical Systems, Vol 6 , p 307-327.

Burtscher, H. (2005): Physical characterization of particulate emissions from diesel engines: a review. Journal of Aerosol Science, Vol36, n7, p 896-932.

Fuller, K. A., Malm, W. C., \& Kreidenweis, S. M. (1999): Effects of mixing on extinction by carbonaceous particles. Journal of Geophysical Research, Vol 104, n¹5, p 941-954.

Grob B., Schmid J., Ivleva N.P. \& Niessner R. (2012): Conductivity for Soot Sensing: Possibilities and Limitations, Anal. Chem., Vol 84, p 3586-3592.

Hagen G., Feistkorn C., Wiegärtner S., Heinrich A., Brüggemann D. \& Moos R. (2010): Conductometric Soot Sensor for Automotive Exhausts: Initial Studies. Sensors, Vol. 10, p 15891598.

Husted H., Roth G., Nelson S., Hocken L., Fulks G. \& Racine D. (2012): Sensing of Particulate Matter for On-Board Diagnosis of Particulate Filters. SAE Int. J. Engines, Vol 5, p 235-247.

Ivleva, N. P., Messerer, A., Yang, X., Niessner, R., \& Pöschl, U. (2007): Raman microspectroscopic analysis of changes in the chemical structure and reactivity of soot in a diesel exhaust aftertreatment model system. Environmental science \& technology, Vol 41, n¹0, p 3702-3707.

Liati, A., Eggenschwiler, P. D., Schreiber, D., Zelenay, V., \& Ammann, M. (2013): Variations in diesel soot reactivity along the exhaust after-treatment system, based on the morphology and nanostructure of primary soot particles. Combustion and Flame, Vol 160, n`3, p 671-681.

Lopez-Gonzalez D., Tsampas M.N., Boréave A., Retailleau-Mevel L., Klotz M., Tardivat C., Cartoixa B., Pajot K. \& Vernoux P. (2015): Mixed Ionic-Electronic Conducting Catalysts for Catalysed Gasoline Particulate Filters. Top. Catal., Vol 58,n¹8, p 1242-1255.

Moore, R. H., Ziemba, L. D., Dutcher, D., Beyersdorf, A. J., Chan, K., Crumeyrolle, S., ... \& Anderson, B. E. (2014): Mapping the operation of the miniature combustion aerosol standard (Mini-CAST) soot generator. Aerosol Science and Technology, Vol48, n5, p 467-479.

Noulette J. \& Duault F. (2014): Sonde de mesure de depot de suie dans l'echappement et son procede de fabrication. WO2014044965 A1, 2014. http://www.google.com/patents/WO2014044965A1 (accessed June 29, 2015).

Ntziachristos, L., Amanatidis, S., Samaras, Z., Janka, K., \& Tikkanen, J. (2013): Application of the Pegasor Particle Sensor for the measurement of mass and particle number emissions. SAE International Journal of Fuels and Lubricants, Vol 6, n², p 521-531.

Ochs T., Schittenhelm H., Genssle A. \& Kamp B. (2010): Particulate Matter Sensor for On Board Diagnostics (OBD) of Diesel Particulate Filters (DPF). SAE Int. J. Fuels Lubr., Vol 3, p 61-69.

Petzold, A., \& Schönlinner, M. (2004): Multi-angle absorption photometry-a new method for the measurement of aerosol light absorption and atmospheric black carbon. Journal of Aerosol Science, Vol 35, n4, p 421-441.

Sadezky, A., Muckenhuber, H., Grothe, H., Niessner, R., \& Pöschl, U. (2005): Raman microspectroscopy of soot and related carbonaceous materials: spectral analysis and structural information. Carbon, Vol 43, n8, p 1731-1742.

Uy, D., Ford, M. A., Jayne, D. T., Haack, L. P., Hangas, J., Jagner, M. J., ... \& Gangopadhyay, A. K. (2014): Characterization of gasoline soot and comparison to diesel soot: Morphology, chemistry, and wear. Tribology International, Vol 80, p 198-209.

Walker A.P. (2004): Controlling Particulate Emissions from Diesel Vehicles, Topics in Catalysis, Vol. 28, n¹, p 165-170. 